\title{
Medidas para afrontar la SeQuía en MéXico: UNA VISIÓN RETROSPECTIVA
}

\author{
Measures to cope with drought in Mexico: \\ A retrospective view
}

DaVid ORTEGA-GAUCIN*

\section{RESUMEN}

La sequía es uno de los fenómenos naturales más complejos y que afecta a más personas en el mundo. El objetivo de este artículo es presentar una revisión de las principales medidas que han sido implementadas en las distintas etapas de la historia de México (época prehispánica, época colonial, siglos XIX, XX y XXI) para prevenir y mitigar los impactos de la sequía en la sociedad. Como parte de la metodología empleada, se realizó una clasificación de las medidas adoptadas en cada periodo, agrupándolas en dos grandes categorías: preventivas (las que se han implantado mucho antes de que suceda una sequía) y reactivas (las que se han adoptado durante el evento de sequía); a su vez, ambos tipos de medidas se subdividen en medidas sociales, tecnológicas y gubernamentales. La originalidad de esta aportación se basa en exponer que, pese a la lucha histórica de México frente a la sequía, esta no ha dejado ni dejará de ser un problema capital, por lo que es sustancial que tanto las autoridades gubernamentales como la población en general sean conscientes de la vulnerabilidad ante el peligro y de la importancia de adoptar medidas preventivas y de adaptación que conduzcan a una gestión apropiada del riesgo. Se concluye que, aunque en la actualidad tenemos mayor conocimiento científico y desarrollo tecnológico para hacer frente a la sequía, estas herramientas no constituyen por sí mismas la solución al problema, sino que son el complemento de otras acciones y estrategias de corte político, económico y social que en conjunto ayudan a contrarrestar los efectos negativos del fenómeno.

Palabras clave: seluía, historia de México, usos del agua, vulnerabilidad, desastre.

\footnotetext{
* Instituto Mexicano de Tecnología del Agua, Coordinación de Hidrología. Correo electrónico: dortega@ tlaloc.imta.mx.
} 


\section{Abstract}

Drought is one of the most complex and natural phenomena that affects more people in the world. The aim of this article is to present a review of the main measures that have been implemented in the different stages of the history of Mexico (pre-hispanic, colonial, XIX, $\mathrm{XX}$ and XXI) to prevent and mitigate the impacts of drought in the society. As part of the methodology used was a classification of the measures taken in each period, grouped into two broad categories: preventive measures (those that have been in place long before it happens a drought) and reactive (which have been taken during the event of drought); in turn, both types of measures are further subdivided in social, technological and governmental measures. The originality of this contribution is based on that in spite of the historic struggle of Mexico vis-à-vis the drought, this has not stopped will cease to be a problem, so it is substantial, that both the government authorities and the population in general are aware of the vulnerability in the face of danger, and of the importance of preventive measures and adaptation that will lead to a proper risk management. It is concluded that, although at present we have greater scientific knowledge and technological development to cope with drought, these tools do not constitute itself the solution to the problem, but, rather, they are the complement of other actions and strategies of political, economic and social nature which together help to counteract the negative effects of the phenomenon.

KEYWORDS: DROUGHT, HISTORY OF MEXICO, WATER USES, VULNERABILITY, DISASTER.

Recepción: 29 de febrero de 2016.

Dictamen 1: 6 de junio de 2016.

Dictamen 2: 17 de octubre de 2016.

Dictamen 3: 8 de noviembre de 2016. 


\section{INTRODUCCIÓN}

La sequía es uno de los fenómenos naturales que más daños han causado a la población mundial (WMO, 2006). Es parte intrínseca del clima, por lo que todos los lugares del planeta están expuestos a su eventual ocurrencia, incluso las zonas distintivamente lluviosas (Wilhite, 2000). Sus efectos van desde aquellos de carácter físico a corto plazo (escasez o falta de agua para las actividades cotidianas) y ambiental (daños en la flora y fauna silvestres) hasta los impactos sociales y económicos de gran alcance como son pérdidas de la producción agrícola, pecuaria, forestal y pesquera; desempleo; conflictos por el agua, entre otros (Ortega-Gaucin y Velasco, 2013).

En el mundo, se estima que alrededor de una quinta parte de las pérdidas económicas provocadas por fenómenos naturales se atribuyen a las sequías (WMO, 2006). En efecto, las sequías pueden tener una incidencia global muy negativa en la economía tanto de los países desarrollados como en vías de desarrollo. Por ejemplo, en Estados Unidos, la nación más poderosa del mundo, las sequías son causantes de los desastres más costosos asociados a fenómenos naturales, que han llegado a provocar pérdidas en los diferentes sectores económicos de hasta ocho mil millones de dólares anuales (Wilhite, 2000; Cook et al., 2007). Mientras tanto, en países mucho más pobres como Nigeria y Níger, en África, las sequías pueden provocar la reducción anual de hasta nueve por ciento de su producto interno bruto (WMO, 2006).

México, país en vías de desarrollo, no está exento de padecer las acometidas de las sequías con cierta periodicidad, como lo muestra la última sequía ocurrida durante los años 2011 y 2012, la cual, por sus efectos negativos en los diversos sectores socioeconómicos, ha sido evaluada como la más grave de las últimas siete décadas. Esta sequía afectó más de 80 por ciento del territorio nacional y causó pérdidas superiores a 16 mil millones de pesos tan solo en el sector agropecuario; además, provocó serios problemas de desabasto de agua en las comunidades rurales de las regiones más áridas y vulnerables del país (INEGI, 2013).

La sequía no es un problema reciente en México, pues esta ha sido una dificultad frecuente y persistente durante toda la historia del desarrollo nacional, como lo ponen de manifiesto los registros de las sequías acontecidas desde la época prehispánica. Documentos antiguos señalan que la sequía fue una de las peores adversidades de los pueblos, que perturbaba la agricultura y la vida de los habitantes provocando hambre, migración y muerte (Castorena, 1980; Florescano et al., 
1980; García, 1993; Florescano, 2000; García et al., 2003; Gill, 2008). Incluso, existen teorías que sostienen que la sequía fue la causa de la desaparición de algunas civilizaciones precolombinas, como la maya o la teotihuacana (Culbert, 1973; Dalhin, 1983; Hodell et al., 1995; Rodríguez y MacLachlan, 2001; Gill, 2008), aunque estas teorías no han sido comprobadas plenamente.

Durante la época colonial y en el periodo independiente, la sequía estuvo presente en diferentes momentos de la historia del país y provocó escasez de granos, carestía de alimentos, crisis agrícolas y hambrunas (Castorena, 1980; Florescano, 1986; Aboites y Camacho, 1996; Molina, 1996). Además, existen pruebas históricas que permiten inferir que las sequías ocurridas en los años previos a los movimientos de Independencia de 1810 y de Revolución de 1910 influyeron en su desencadenamiento (García, 1993; Escobar, 1997; Florescano, 2000).

En este contexto, el presente artículo tiene como objetivo exponer las principales medidas que han sido implementadas en las diferentes etapas de la historia de México (desde la época prehispánica hasta la actualidad) para gestionar las sequías, es decir, para prevenir y mitigar los impactos del fenómeno. Para lograr este cometido, el estudio ha sido dividido en una periodización convencional a fin de establecer un orden cronológico en la investigación: época prehispánica, época colonial (virreinato), México decimonónico (siglo XIX), siglo XX y siglo XXI. El procedimiento de recopilación de la información consistió básicamente en una revisión bibliográfica (artículos y libros) de los principales historiadores que han escrito sobre el tema de la sequía en México para las épocas prehispánica, colonial, siglo XIX y siglo XX; y una revisión documental (informes técnicos y publicaciones oficiales, primordialmente) para dar cuenta de las medidas adoptadas para paliar la sequía en lo que va del presente siglo. Dado que el periodo de estudio que abarca este artículo es bastante amplio — como también lo es el área geográfica de México-, no se pretende incluir una revisión exhaustiva de las medidas adoptadas en cada época y en cada región del país, sino más bien hacer una descripción y clasificación general de estas, anotando ejemplos de las más comunes o sobresalientes en cada etapa.

El artículo está estructurado de la siguiente manera: en el siguiente apartado se presenta un breve marco teórico, en el cual se describe la sequía como fenómeno natural y las diferentes formas de concebirlo (esto será útil, más adelante, para entender las diferentes asimilaciones etiológicas y las respectivas respuestas de las sociedades a través del tiempo); luego se propone una clasificación general de los modelos históricos para afrontar las sequías en México; posteriormente se despliegan los apartados que describen las diversas medidas implementadas en las distintas 
épocas del desarrollo del país; después se incluye la discusión, en la que se enuncian algunas consideraciones derivadas del estudio; finalmente, las conclusiones y la relación de las fuentes consultadas.

\section{El FENÓMENO DE LA SEQUía: \\ DE LA ATRIBUCIÓN DIVINA A LA COMPRENSIÓN CIENTÍFICA}

La concepción y el entendimiento de los fenómenos naturales ha variado mucho a través de los siglos. En tiempos ancestrales, se consideraba que los peligros de la naturaleza, tales como tormentas, tornados o terremotos, eran provocados por la furia de los dioses contra los pueblos y las naciones (Gaarder, 2012). Ello provenía de la necesidad humana de darle sentido a los hechos, sobre todo a aquellos capaces de provocar muerte (Ayala Carcedo, 2002). Sin embargo, aún en la actualidad, una gran proporción de la población mundial sigue creyendo que estos fenómenos son atribuibles a causas divinas. Por ejemplo, la inundación provocada en 2008 por el río Kosi, en la India, fue imputada por muchos de sus habitantes a la ira de una diosa; o cuando ocurrió el tsunami que devastó Aceh, Indonesia, en 2004, numerosos pobladores creyeron que Alá les había enviado un castigo por haber permitido el turismo y la perforación de pozos petroleros (IFRC, 2014). Lo anterior es comprensible si se toma en cuenta el papel tan importante que desde siempre han tenido las distintas creencias y religiones en la vida social.

El entendimiento del fenómeno de la sequía no es la excepción. La ausencia de lluvias durante periodos prolongados ha sido atribuida por diversas culturas a la voluntad de los dioses. Por ejemplo, en la mitología egipcia existía el dios Set o Seth, deidad brutal de la sequía y del desierto. Por su parte, en la mitología de culturas mesoamericanas como la azteca o la maya, la creencia en dioses de la lluvia como Tláloc o Chac es una evidencia clara del miedo ancestral que nuestros antepasados le tenían a la falta de agua (Moreno, 2004). Por otro lado, en las tierras bíblicas la sequía era considerada un castigo de Jehová por los errores o pecados del pueblo (Hageo 1:7-11, Jeremías 14:1-6). Debido al amplio esparcimiento del judaísmo y del cristianismo -y de las innumerables religiones derivadas de estas corrientesesta creencia ha persistido en amplios sectores de la población desde los tiempos bíblicos hasta la actualidad.

No obstante, en el campo técnico-científico, hoy se reconoce que la sequía es un fenómeno natural que forma parte de la variabilidad del clima, que responde 
a muy diversas causas de origen natural según la región donde se presente, tales como las variaciones en la actividad solar, los cambios en los patrones de circulación de la atmósfera y los fenómenos globales de interacción entre los océanos y la atmósfera, como El Niño/Oscilación del Sur (Lean y Rind, 2001; Schubert et al., 2004; Sheffield et al., 2009). Además, en tiempos recientes se ha reconocido que factores antropogénicos como la deforestación, la degradación ambiental y el cambio climático global —imputado principalmente a las actividades humanas que implican la quema de combustibles fósiles y su consecuente liberación de grandes cantidades de gases de efecto invernadero hacia la atmósfera- han traído como consecuencia una mayor frecuencia y severidad de las sequías ocurridas en las últimas décadas (Mishra y Singh, 2009; IPCC, 2014).

Con independencia de las causas que se le atribuyan, lo cierto es que la sequía es uno de los fenómenos más complejos y es tal vez el menos comprendido de todos los peligros naturales (Wilhite, 2000). Ello se debe a que se trata de un fenómeno relativo, cuyas características varían mucho de un lugar a otro y para el cual no existe una definición única y precisa aplicable a todos los ámbitos, sino que depende de la ubicación y percepción de la población que lo padece (Velasco et al., 2005). Así, comúnmente se habla de sequía desde los puntos de vista meteorológico, agrícola, hidrológico y socioeconómico (WMO, 2006). A diferencia de otros fenómenos naturales cuyos efectos son locales y de corto plazo (los huracanes o los tornados, por ejemplo), las sequías se extienden en grandes áreas geográficas y sus consecuencias pueden prevalecer por varios años, con un efecto negativo en la calidad de vida y en el desarrollo de las poblaciones afectadas (Wilhite y Vanyarkho, 2000). Además, las sequías carecen de epicentro y trayectorias definidas, evolucionan de manera lenta y gradual, por lo que es difícil identificar el momento de su inicio y no se sabe con certeza cuándo será su final (Below et al., 2007). De igual forma, estas características hacen que las sequías hasta el día de hoy sean difícilmente predecibles y potencialmente catastróficas (Kim et al., 2002).

Los impactos de la sequía no solo dependen de las características físicas y temporales del fenómeno, es decir, del grado de disminución de la lluvia, de su duración o de su extensión geográfica, sino también del nivel de desarrollo socioeconómico y tecnológico de las áreas afectadas, del equilibrio entre la disponibilidad y la demanda del recurso hídrico para la permanencia de los ecosistemas y para la realización de las actividades humanas, así como de la habilidad de las comunidades y los gobiernos para implementar acciones y estrategias adecuadas que permitan prevenir y paliar sus impactos (Ortega-Gaucin, 2012). Por ello, debido a que los efectos de la sequía 
sobre la población dependen en gran medida de factores humanos, históricamente las personas y comunidades han respondido al fenómeno en función de una variedad de elementos típicamente relacionados con la cultura, la percepción del peligro y la organización social imperante en el momento en que ocurre.

En este contexto, lo cierto es que no es posible evitar la ocurrencia de las sequías, pero hay maneras de prevenir y mitigar sus efectos negativos, así como disminuir las pérdidas de los afectados por el fenómeno, es decir, hay maneras de gestionar las sequías. La gestión de sequías se refiere a todas aquellas acciones y respuestas sociales, técnicas (ingenieriles) e institucionales (económicas, políticas) que se ponen en práctica para afrontar situaciones de sequía (WMO, 2012), ya sea con antelación al inicio del fenómeno (medidas preventivas) o cuando ya está presente (medidas reactivas). Así, desde siempre, las diversas civilizaciones han efectuado una gran variedad de acciones y estrategias con este propósito. En este artículo se analiza el caso de México.

\section{Modelos HistóRICOS PARA AFRONTAR LAS SEQUías EN MÉXICO}

En general, las sociedades antiguas y modernas de México han diseñado y utilizado distintos tipos de estrategias para afrontar las sequías, las cuales pueden ser agrupadas en dos grandes categorías: preventivas y reactivas, tal como se ilustra en la figura 1.

\section{Figura 1. ClasificaCión de LAS MEDidas} PARA AFRONTAR LOS IMPACTOS DE LAS SEQUÍAS

Medidas para
$\begin{aligned} & \text { afrontar los impactos } \\ & \text { de la sequía }\end{aligned}$$\left\{\begin{array}{l}\begin{array}{l}\text { Medidas } \\ \text { preventivas } \\ \text { Tecnológicas } \\ \text { Gubernamentales } \\ \text { Medidas } \\ \text { reactivas }\end{array} \\ \text { Tecnológicas } \\ \text { Gubernamentales }\end{array}\right.$


Las medidas preventivas son aquellas que se han implantado mucho antes de que suceda una sequía, y han tenido como finalidad estar preparados para afrontar la escasez y falta de agua provocada por el fenómeno. Por su parte, las medidas reactivas se refieren a las que se han adoptado durante el periodo de sequía, y han implicado que la comunidad y el gobierno actúen haciendo algo al respecto para aminorar sus efectos negativos. Ambos tipos de medidas se pueden dividir, a su vez, en tres categorías: sociales, tecnológicas y gubernamentales.

- Medidas sociales. Son las que se han llevado a cabo de manera independiente u organizada por los miembros de la sociedad civil para tratar de prevenir o aminorar los efectos de la sequía en la vida social. Estas van desde la celebración de ceremonias religiosas dirigidas a los dioses en la época prehispánica para propiciar las lluvias, hasta los festivales dirigidos a los santos en la actualidad, pasando por las procesiones y rogativas en el virreinato y la participación de la Iglesia para ayudar a los necesitados en el México decimonónico.

- Medidas tecnológicas. Se refieren a las que se han basado en el diseño y uso de diversos tipos de técnicas, métodos, obras y dispositivos para captar, almacenar y aprovechar mejor el agua en épocas de escasez y sequía. Estas van desde los "chultunes" (sistemas de captación y almacenamiento de agua de lluvia) de la época prehispánica hasta las grandes presas de la actualidad, pasando por las acequias, apantles, jagüeyes, aljibes, cisternas, pilas, etcétera, que se utilizan hasta el día de hoy. Incluyen las investigaciones que se han llevado a cabo desde el siglo pasado para provocar la lluvia o para crear semillas resistentes a la sequía mediante manipulaciones genéticas.

- Medidas gubernamentales. Son las acciones, regulaciones y políticas públicas que han sido instauradas por las autoridades estatales o nacionales para prevenir y mitigar los efectos de la sequía en la economía y en la sociedad. Estas van desde la imposición de tributos en especie (maíz y otros granos) para los indígenas en la época colonial, o la creación de grandes almacenes de depósito de granos en la misma época, hasta la formulación de programas gubernamentales contra la sequía en la actualidad, pasando por los controles de precios y la importación de alimentos en épocas de crisis, así como diversas formas de ayuda asistencial a la población afectada por sequías.

Los diferentes tipos de medidas descritos anteriormente han sido utilizados en distintos momentos de la historia de México, ya sea de manera conjunta o por 
separado, tal como se describe de modo puntual en las siguientes secciones, las cuales se han organizado siguiendo la periodización mencionada en la introducción de este artículo.

\section{MEdidAS CONTRA LA SEQUía EN LA ÉPOCA PREHISPÁNICA}

Las civilizaciones precolombinas buscaban contrarrestar los impactos de las sequías mediante acciones de carácter sobrenatural: la celebración de múltiples ceremonias religiosas dirigidas a sus distintos dioses y prácticas mágicas para regular ritualmente el ciclo agrícola (García, 1993; Florescano, 2000). Entre los mixtecas, por ejemplo, se hacían festivales dirigidos a Tláloc, dios de las lluvias, el rayo y las tempestades. De igual modo, se hacían festivales dirigidos a Chalchiuhtlicue, diosa de las aguas terrenales (mares, lagos, ríos, torrentes y manantiales), quien era considerada la esposa o hermana de Tláloc. Esta diosa era reverenciada, en general, en todas partes donde se tenía agua aprovechable, y la honraban con esculturas a las que ofrendaban los mismos productos del agua, flores, joyas y sacrificios de animales y humanos (Kroger y Granziera, 2012). Asimismo, los mixtecas practicaban la adivinación para predecir desastres o épocas malas, y eventualmente sacrificaban recién nacidos y niños para propiciar las lluvias. Por ejemplo, el Códice Ramírez documenta la terrible sequía de 14501454 que causó hambruna y emigración en el Valle de México. Aunque el Imperio Azteca distribuía maíz de graneros centrales en tiempos de hambre, la sequía de 1454 fue tan severa que la gente se vendía a sí misma o a sus hijos como esclavos y se hacían sacrificios humanos a los dioses de la lluvia (Florescano et al., 1980; Sancho y Pérez Gavilán, 1981; Musset, 1991).

Los mayas, al igual que los mexicas, tenían sus propios dioses a quienes asociaban con los distintos fenómenos hidrometeorológicos, por ejemplo, Chac, dios de la lluvia, del trueno y del relámpago, o Gucomatz, dios de la tempestad. Las cuevas, caracterizadas por tener abundante humedad relativa y rocío condensado (en ocasiones atravesadas por ríos subterráneos formados por la infiltración de la precipitación en suelo kárstico), eran consideradas el hogar de estos dioses, por lo que se piensa que los rituales celebrados dentro de ellas sugieren que podrían haber sido intentos de generar lluvia en las épocas secas. Según el Libro de Chilam Balam de Maní, los mayas se retiraron a sus cuevas en tiempos de sequía, donde vivieron, oraron y murieron (Bassie Sweet, 1991). 
Además de los rituales y ceremonias dirigidas a los dioses, en todos los pueblos antiguos de Mesoamérica se implementó otro tipo de medidas tecnológicas para afrontar la sequía, entre las cuales se encuentran, por ejemplo, la construcción de observatorios astronómicos para ayudar a predecir el clima (Liverman, 2000). Así, estas sociedades crearon una ciencia, la astronomía, dedicada a estudiar las relaciones entre los fenómenos meteorológicos y el ciclo agrícola (Florescano et al., 1980). Igualmente, a lo largo del imperio mexica se construyeron trojes en donde se al macenaba el maíz, que servía para sortear la falta de alimento durante un año; el grano almacenado se repartía en épocas de escasez a los necesitados, según el principio de reciprocidad social entre gobernantes y gobernados que caracterizó al mundo indígena (García, 1993).

Asimismo, durante la época prehispánica se efectuaron diversas medidas prácticas para hacer un mejor uso y aprovechamiento del agua, las cuales permitieron sortear periodos de escasez de agua provocados por sequía. Por ejemplo, se empleó una extraordinaria variedad de técnicas hidroagrícolas que van desde ingeniosos sistemas para colectar y conservar el agua de la lluvia hasta la excavación de pozos y la apertura de acequias desde los lagos para regar a brazo las huertas; incluso los setos vivos o de piedra, la construcción de terrazas agrícolas y de bancales deben considerarse, en muchos casos, como técnicas deliberadas de control de humedad del suelo y como maneras planeadas de retener y dirigir el agua de lluvia (Palerm, 1954 y 2007; Enge y Whiteford 1989; Wilken 1987). Así surgieron los primeros sistemas de irrigación, por lo que la agricultura de riego se practicaba entre los mexicas mucho antes de la llegada de los españoles (Palerm, 1954 y 1969). Por todas partes había pequeños diques y canales que servían para almacenar el agua y conducirla hasta las tierras que la necesitaban, con lo cual se protegían las primeras cosechas de las amenazas de la sequía y se ayudaba a la segunda cosecha a crecer en un suelo que de otra manera permanecería estéril (Wolf, 1967; Palerm y Wolf, 1972).

En el área de la civilización maya, el reto para los pobladores, no solo era cómo protegerse de la estación seca (es decir, la época de estiaje), sino también cómo lidiar con periodos de precipitación extremadamente baja o nula. La carencia absoluta de acceso a cualquier fuente de agua obligó a los pobladores de esta zona a construir instalaciones bien diseñadas para guardar agua, llamadas chultunes (precursores de las cisternas modernas), cuyo fin era almacenar agua para ser utilizada en tiempos de lluvias escasas (Zapata, 1982; Gill, 2008). 


\section{Medidas Para afrontar la SEQuía En EL VirReinato}

Entre las estrategias puestas en práctica para aminorar los impactos de la sequía en esta época, la religión católica desempeñó un papel preponderante, pues ayudaba a reducir las tensiones sociales provocadas por la falta de lluvias, a través de plegarias, procesiones y misas, principalmente. Por ejemplo, en la Villa de Saltillo, Coahuila, para reducir los efectos de una "terrible seca" se celebró un novenario de misas dedicadas al Señor Cristo de la Parroquia, se realizó una procesión pública y otras ceremonias con cargo a las aportaciones de los feligreses (García, 1997; García et al., 2003).

De igual modo, era común que los administradores de las haciendas confiaran la abundancia de la cosecha a Dios, a la Virgen de Guadalupe o a los santos patronos locales. En ocasiones, se pagaba a un cura para que exorcizara los fenómenos naturales como las heladas, el granizo y otras amenazas para la agricultura. Para los hacendados, lo más convincente era invocar la protección de Santa Teresa o de la Virgen de los Remedios, la santa patrona de la lluvia, la cual, de acuerdo con la tradición medieval, era la intermediaria más eficiente en estos asuntos (Hernández, 1982; García, 1993; Florescano, 2000; García et al., 2003). Incluso, existen investigaciones que han determinado la frecuencia y la duración de las sequías en la cuenca del Valle de México desde el siglo XVI hasta el XIX mediante la cuantificación de las ceremonias denominadas rogativas (que fueron registradas en forma constante en las actas de los Cabildos religioso y civil de la Ciudad de México), las cuales tenían como propósito solicitar, sobre todo a la Virgen de los Remedios, el fin de una vicisitud ambiental o mórbida como lo era una sequía (Garza, 2002).

Por otro lado, cuando los alimentos escaseaban en las ciudades a consecuencia de la sequía, se pedían tributos en especie (maíz) a los indígenas, en lugar de dinero, ${ }^{1}$ y se prohibía que se instalaran algunos tianguis que se celebraban periódicamente en diversos pueblos cercanos a la ciudad de México a fin de obligar a los indígenas a llevar sus productos hasta el mercado de la capital. Al mismo tiempo, se ponían en práctica medidas para combatir el acaparamiento de granos (maíz y trigo) y la especulación por parte de los encomenderos y los corregidores, autoridades españolas encargadas de proteger a los indios, hacer justicia y recibir los tributos reales (Florescano, 2000; García et al., 2003). Por ejemplo, en la ciudad de México, se

${ }^{1}$ Hubo ocasiones en que las autoridades llegaron a conmutar el tributo a pueblos cuando comprobaban que no podían rendirlo, ya sea por causa de la disminución de la población o cuando existieron grandes sequías y hambres (Quezada, 1996). 
fundaron dos instituciones con este propósito: el pósito y la alhóndiga. El pósito nació por decisión del cabildo de la ciudad de México, y su función era asegurar a los grupos de bajo ingreso la compra de cereal. Era una institución de beneficencia pública, por lo cual las ordenanzas mandaban que los granos del pósito se reservaran a la población más pobre y a los indios. Por su parte, la alhóndiga se había pensado como un complemento del pósito: era un almacén de depósito público donde deberían llevarse y venderse todos los granos introducidos a la ciudad, con lo cual se buscaba evitar la venta libre y arbitraria de estos, eliminar a los intermediarios y evitar el acaparamiento en las casas de los particulares (Vázquez, 1968).

No obstante, los hacendados habían adquirido cada vez mayor control sobre la oferta de granos y el alza de los precios, así como el dominio del pósito y de la alhóndiga, gracias al poder político y económico que tenían, pues con frecuencia ocupaban los principales cargos del Cabildo de la ciudad, y lograban acumular excedentes de sus propias cosechas. A pesar de todo, el pósito y la alhóndiga cumplieron, hasta cierto punto, sus propósitos originales en los años de crisis y carestía, ya que aseguraban el suministro de granos a la población y atenuaban los efectos de la escasez (Molina, 1996).

En esa época también se instauró otro tipo de ordenanzas por parte de las autoridades coloniales para hacer frente a las sequías. Por ejemplo, en la Villa de Saltillo, Coahuila, con frecuencia se establecían controles de las siembras para regular la cantidad de cultivos que se sembraban; se imponía la contribución forzosa para los hacendados más prominentes; se prohibía la extracción de granos de la villa para evitar el desabasto y el aumento de precios de los productos básicos; se inspeccionaban las cantidades de las cosechas y de las reservas. Además, se instauró la llamada "alhóndiga provisional" con el propósito de regular el suministro y el precio de las semillas (García, 1997; García et al., 2003).

Finalmente, cabe mencionar que durante la época colonial se efectuaron diversas obras hidráulicas que, de manera directa o indirecta, permitieron combatir la escasez de agua provocada por las frecuentes sequías. Estas obras incluyen, por ejemplo, los jagüeyes, pozos, acueductos, canales, presas de almacenamiento, presas derivadoras, superficies para recolectar agua de lluvia (impluvio) en techos de casas y patios, diques y calzadas-diques y depósitos de almacenamiento (aljibes, cisternas, pilas, etcétera) (Toussainnt, 1974; Galván, 1998; Doolittle, 1999; Rojas, 2009). 


\section{MEdidAS CONTRA LA SEQUía EN}

\section{EL MÉXICO DECIMONÓNICO (SIGLO XIX)}

Muchas de las medidas para combatir las sequías adoptadas durante el siglo XIX fueron semejantes a las de la época colonial; por ejemplo, se recurrió a la religión, al control de precios y a la importación de semillas como medidas para paliar la crisis. Con respecto del papel que desempeñó la religión en esta época, la Iglesia participaba de forma material y espiritual. En el aspecto material, donaba dinero para la compra de semillas, creaba comedores públicos para los necesitados y dispensaba productos agrícolas recabados por el diezmo para que se vendieran a un precio inferior al de mercado. Por el lado espiritual, participaba con procesiones y rogativas para implorar el socorro divino, aunque ya en esos tiempos las ceremonias religiosas en lugares públicos estaban prohibidas por las leyes federales. Al respecto, se citan dos ejemplos: en 1866 se celebró un novenario en honor a la Señora de Guanajuato con el propósito de solicitar su intervención para que lloviera; y, en agosto de 1891, las campanas de la parroquia de Durango no cesaban de sonar llamando a los fieles a rogativas, novenarios y triduos para solicitar las lluvias (Escobar, 1997 y 2004).

En cuanto al control de precios y de la existencia de granos como estrategias para mitigar los efectos de la sequía, se pueden ejemplificar con la sequía de 18491851 que afectó principalmente a los estados del norte del país. Durante esta crisis agrícola, las autoridades del gobierno de Durango ordenaron a los hacendados y rancheros de la jurisdicción entregar una relación jurada de las existencias de maíz, frijol y trigo, así como de las cantidades que requerían para las raciones de sus trabajadores. En la misma crisis, el estado de Coahuila amortiguó las tendencias del alza de los precios fijando el costo del almud de maíz a cuatro reales (Del Bajío, 1987).

Para reducir los efectos inmediatos de las sequías, una medida adicional consistía en la importación de granos de otras entidades federativas de la república o bien de Estados Unidos. Por ejemplo, entre 1822 y 1835, para resarcir la situación en Yucatán, el gobierno federal promovió la importación libre de cereales cada vez que la agricultura era dañada por la sequía en la región (Padilla et al., 1980). Durante la sequía de 1849-1851, el gobierno federal autorizó a los gobiernos de Nuevo León y Tamaulipas importar víveres del extranjero (maíz, frijol, harina y manteca). En la crisis de 1891-1892 se produjo la importación más cuantiosa de maíz y trigo de Estados Unidos hacia México, debido a que se decretó una ley que permitía que casi todos los estados de la república pudieran comprar semillas de origen estadounidense (Escobar, 1997 y 2004). 
Al abolirse el pósito y la alhóndiga a raíz de la Independencia se intentó fundar instituciones similares en distintos estados. En los puertos de San Blas, Acapulco y Veracruz se establecieron los llamados “puertos de depósito", creados por iniciativa del gobierno federal en 1837, para hacerse cargo de almacenar alimentos importados para afrontar las épocas de crisis (Del Bajío, 1987). Asimismo, con el propósito de aminorar los efectos sociales de las sequías, en 1888 se fundaron los Almacenes Generales de Depósito, mediante los cuales se buscaba disminuir las secuelas de los años de malas cosechas (Florescano, 2000). Con todo, estos esfuerzos no fueron suficientes, pues las sequías continuaron afectando a la población más necesitada.

A finales del siglo XIX, aunque la sequía rara vez afectó a los agricultores, estos demandaron constantemente que los fondos del gobierno se destinaran a lo que ellos consideraban obras necesarias, como las de irrigación. En ese tiempo se construyeron los primeros canales para riego en la Comarca Lagunera, en el Valle de Mexicali y en la parte baja de la cuenca del río Bravo (Florescano, 2000). No obstante, se estima que a principios del siglo XX apenas unas 750 mil hectáreas se hallaban cultivadas con riego en toda la república (Sánchez, 2009), es decir, la mayor parte de la tierra se sembraba con cultivos de temporal. Por otro lado, para mitigar los impactos de las sequías en el sector ganadero, se construyeron abrevaderos en los que se captaba y almacenaba el agua durante la época de lluvias para hacer frente a la estación seca del año. Asimismo, fue práctica común arrear el ganado a regiones menos castigadas por la sequía y vender la mayor parte de los rebaños antes de que las condiciones empeoraran.

Con los inicios del porfiriato en 1876, comenzó la construcción de una importante infraestructura que, de manera directa o indirecta, permitió la mitigación de los impactos de las recurrentes crisis agrícolas ocasionadas por las sequías. Por ejemplo, las mejoras en los caminos y el desarrollo del ferrocarril, aunque no abarcaron el país en su conjunto, hicieron posible la transportación de manera más rápida, eficiente y económica de los bienes de las zonas de producción a las áreas de desastre. Igualmente, el puente ferroviario tendido entre el noroeste de México y el suroeste de Estados Unidos facilitó el inicio de la importación de granos desde ese país (Gresham, 1975).

\section{MEdidAS CONTRA LA SEQUía EN EL SIGLO XX}

Durante el siglo XX, la religión siguió desempañando un papel importante en las medidas previstas por la población para paliar los impactos de la sequía. Por 
ejemplo, ante la grave sequía de 1950 en Jalisco, los feligreses sacaban a la Virgen de Zapopan de su santuario para realizar procesiones implorando por la lluvia (Aboites y Camacho, 1996). En 1955, tras varios años de sequía que amenazaba la extinción del lago de Chapala, la imagen de la virgen mencionada fue llevada al vaso del lago para pedir un buen temporal de lluvias, con lo que se logró una asombrosa recuperación del embalse (Ceja, 2011). Desde entonces, año con año se celebra en el mismo lugar una festividad en honor de esta virgen para solicitar su intermediación ante la Divina Providencia por la sana supervivencia y el auge del vaso lacustre más grande del país (Alcalá y Ceja, 2014).

En esa época, cuando la sequía provocaba insuficiencia de granos y otros víveres, se recurría al mercado internacional de alimentos, aun en grandes proporciones. Hacia 1950, México era ya un gran importador de alimentos, según lo muestra la estadística de la balanza comercial (Aboites y Camacho, 1996). Durante la sequía de 1949-1958, las importaciones de trigo, maíz y frijol se incrementaron sustancialmente (Reyes, 1974). Incluso, en diciembre de 1952, cuando Adolfo Ruiz Cortínez ocupó la Presidencia de la República, inició un Programa Agrícola de Emergencia para solventar la insuficiencia y carestía de alimentos básicos (Pellicer y Mancilla, 1980).

Por otro lado, la construcción y rehabilitación de obras hidráulicas con fines de irrigación financiadas por el gobierno federal (como son presas, bordos, pozos y la instalación de equipos de bombeo) contribuyeron a disminuir los efectos de la sequía. Aunque la mayoría de ellas formaron parte de la política agraria implementada por los distintos gobiernos a lo largo del siglo XX, con frecuencia estas obras se realizaron con el propósito de reducir las tensiones sociales y políticas provocadas por los malos tiempos. Por ejemplo, en 1952, a raíz de la grave sequía que se vivía en la Región Lagunera (la zona algodonera más importante del país), la Secretaría de Recursos Hidráulicos (SRH) invirtió alrededor de doce millones de pesos para dar empleo diariamente a entre cinco mil y quince mil ejidatarios. Además, se perforaron pozos, se construyeron caminos y carreteras y se realizaron obras de conservación. En ese mismo año, en el distrito de riego de Don Martín, Nuevo León, la presa se secó y las parcelas de cultivo fueron abandonadas, por lo que las autoridades tuvieron que invertir grandes cantidades de dinero para reparar algunas instalaciones de este distrito de riego y, de paso, crear empleos. Lo mismo ocurrió en Río Bravo, Tamaulipas (SRH, 1952).

En ciertos momentos de crisis por la escasez de agua, se adoptaron medidas emergentes para asegurar una distribución adecuada del recurso. Por ejemplo, en 1935, el gobierno de Sonora ordenó que el agua de los pozos y abrevaderos se 
distribuyera entre la gente más necesitada y en las zonas ganaderas (Florescano, 2000). En 1951, ante la necesidad de regar grandes áreas de cultivo de algodón, la SRH construyó una toma de agua en la parte inferior de la presa La Boquilla con el propósito de acceder al volumen "muerto" o de reserva y, de esa manera, irrigar los campos cultivados (Bistráin, 1997). Entre 1948 y 1954, los agricultores de varios lugares del país recurrían cada vez más a la explotación intensiva de los acuíferos para mitigar la grave sequía (Senior, 1956).

Por otra parte, el gobierno federal dispuso otras medidas económicas y sociales para contrarrestar la sequía; por ejemplo, la Secretaría de Agricultura y Ganadería (SAG) conminó al sistema bancario para incrementar el crédito al sector agrícola, como parte del Programa Nacional de Economía Agrícola. Este programa se mantuvo hasta 1970, cuando se instituyó el Plan de Lucha Contra la Sequía, cuya meta fue proveer de trabajo a los desempleados en las áreas de desastre (Castorena, 1980; Florescano et al., 1980).

Finalmente, como parte de las políticas públicas efectuadas por el gobierno federal para mitigar los desastres causados por fenómenos naturales (entre los cuales se encuentra la sequía), a fines del siglo XX, en 1996, se constituyó el denominado Fondo de Desastres Naturales (FONDEN). Este fondo perdura hasta nuestros días y es un instrumento interinstitucional que tiene como objetivo suministrar recursos económicos para dar respuesta a los efectos de los llamados "desastres naturales”. Desde su creación y hasta 2011, el FONDEN destinó en promedio 1.9 por ciento de su presupuesto a la atención de desastres provocados por sequías, lo cual es comprensible si se toma en cuenta que las sequías rara vez ocasionan daños estructurales, pues el FONDEN es un mecanismo financiero que apoya principalmente la reconstrucción de infraestructura pública (puentes, carreteras, etcétera) y vivienda dañada por desastres, por lo que la mayoría de los recursos de este fondo se han asignado a la reconstrucción de obras afectadas por exceso de precipitación pluvial (inundaciones), huracanes y sismos (SEGOB, 2012).

\section{MEDIDAS PARA AFRONTAR LA SEQUíA EN EL SIGLO XXI}

En lo que va del presente siglo, México ha padecido los impactos de la sequía con consecuencias desastrosas en algunos estados del centro y norte del país, principalmente, como sucedió durante la sequía de 2011-2012, que ha sido evaluada como la más severa de las últimas siete décadas (INEGI, 2013). Ante situaciones como esta, 
en la actualidad ciertos sectores de la población siguen recurriendo a la religión y a la intermediación de los santos para tratar de revertir los efectos negativos de la sequía. Por ejemplo, en 2012, en Guanajuato se celebró una misa en la presa del Papalote - que estaba totalmente seca- para pedir por un buen temporal de lluvias, y se realizó una procesión con la imagen de la Madre Santísima de la Luz (Álvarez, 2012). De manera similar, en el lago de Chapala, Jalisco, alrededor de siete mil personas se reunieron en julio de 2013 para pedirle a la Virgen de Zapopan la bendición del lago para su pronta recuperación y un buen temporal agrícola (Melchor, 2013). En mayo de ese mismo año, en Soto La Marina, Tamaulipas, se hizo una procesión en honor a San Isidro Labrador (patrono de los agricultores) para pedir la llegada de las "benditas lluvias", en virtud de que la sequía comenzaba a causar graves estragos en el campo (El Redactor, 2013).

Por su parte, ante la emergencia provocada por las sequías, las autoridades federales y estatales tienden a implementar varios programas emergentes de ayuda humanitaria y agropecuaria, entre los cuales se pueden mencionar los siguientes: reparto de agua en pipas (carros tanque); entrega de despensas, dinero en efectivo o cheques a la población rural y urbana de zonas marginadas; apoyo con suplementos para la alimentación del ganado; programas de empleo temporal (Ortega-Gaucin, 2012). Por ejemplo, ante los severos impactos socioeconómicos y ambientales causados por la sequía en 2011, a principios de 2012 el titular del Ejecutivo federal, Enrique Peña Nieto, instruyó a varias dependencias y Secretarías de Estado la realización de acciones con el propósito de aminorar los impactos de la sequía, para lo cual se les ordenó la agilización del gasto público y la construcción de diversas obras públicas (Presidencia de la República, 2012a). Tan solo en 2012 se erogaron más de 33 mil millones de pesos para mitigar dichos impactos (CONAGUA, 2014).

En noviembre de 2012, el mismo gobierno federal dio a conocer, a través del Diario Oficial de la Federación (DOF), los criterios y mecanismos mediante los cuales la Comisión Nacional del Agua (CONAGUA) puede emitir acuerdos de carácter general por la presencia de sequía (Presidencia de la República, 2012b). Estos lineamientos sirvieron de base para que el presidente de la república anunciara en Zacatecas, el 10 de enero de 2013, la puesta en marcha del Programa Nacional Contra la Sequía (PRONACOSE), designando a la CONAGUA como la dependencia responsable de su coordinación general. Por medio de este programa se pretende transitar de un enfoque reactivo hacia uno preventivo y orientado a la gestión del riesgo de sequía, para lo cual se elaboraron los instrumentos de planeación denominados Programas de Medidas Preventivas y de Mitigación de la 
Sequía (PMPMS) para cada uno de los 26 consejos de cuenca ${ }^{2}$ del país (Arreguín et al., 2015). Asimismo, se creó el Monitor de Sequía de México (MSM), basado en tecnología de punta e imágenes de satélite, como una herramienta de seguimiento y alerta temprana de la sequía en todo el territorio nacional.

De manera paralela a las acciones realizadas como parte del PRONACOSE para auxiliar a la población afectada por sequía, el gobierno federal continúa ejerciendo recursos y apoyando a los afectados a través de otros programas instituidos para atender emergencias climatológicas, como son el Componente de Atención a Desastres Naturales del Sector Agropecuario y Pesquero (CADENA), administrado por la Secretaría de Agricultura, Ganadería, Desarrollo Rural, Pesca y Alimentación (SAGARPA), y el propio FONDEN, de la Secretaría de Gobernación (CONAGUA, 2014).

\section{Discusión}

Del sucinto repaso histórico que se ha realizado en este artículo resulta evidente que, por razones etiológicas diferenciales, en las distintas etapas del desarrollo nacional se ha transitado poco a poco desde una respuesta puramente simbólica ante la sequía hasta la instauración de políticas públicas nacionales para afrontar este fenómeno, pasando por la aplicación de diversos tipos de tecnologías, cuyo avance ha dependido de la época.

En principio, es indudable el papel de la religión —entendida en su sentido más amplio- como una medida para intentar mitigar los efectos de la sequía, desde tiempos ancestrales hasta la actualidad. En este aspecto en particular, pareciera que lo único que ha cambiado a través de los siglos son las formas (tipos de rituales y sacrificios ofrecidos), pero el fondo sigue siendo el mismo: implorar a los seres "superiores" o buscar la intermediación divina para tener abundancia de lluvias y buenas cosechas. Aunque esta concepción y forma de proceder ante la sequía es errónea desde la perspectiva científica actual, ha cumplido la función de posibilitar mecanismos preventivos por medio de ritos propiciatorios o de enmienda que, aun siendo totalmente ilusorios, han proporcionado una seguridad psicológica a

\footnotetext{
2 Aunque limitados en su alcance por su carácter consultivo, los consejos de cuenca son instancias diseñadas para la cogestión del agua; son órganos colegiados integrados de manera mixta entre representantes de los tres niveles de gobierno y la ciudadanía, para coadyuvar a la gestión integrada de los recursos hídricos y restablecer el equilibrio entre su disponibilidad y aprovechamiento (CONAGUA, 2010).
} 
individuos y pueblos indefensos. Esta función de las creencias religiosas, de hecho, sigue estando presente en las sociedades actuales, que continúan creando mitos que toman prestados sus atributos de la propia cultura (Ayala Carcedo, 2002). Es evidentemente que la religión tuvo una importancia mucho mayor durante las épocas prehispánica y colonial, pero a partir del siglo XIX se observa un cambio de una visión religiosa-sobrenatural a una más técnica-gubernamental, y esta tendencia perdura hasta nuestros días.

Por otro lado, respecto del uso de la técnica y la tecnología para contrarrestar la sequía, un aspecto que hay que resaltar y que es común a los diferentes periodos analizados es la construcción de obras hidráulicas que tienen como propósito captar, almacenar, conducir, distribuir y aprovechar el agua con fines agrícolas, pecuarios y de consumo humano. En este rubro, es importante dimensionar de manera adecuada el papel de la sequía en la construcción de estas obras, pues es claro que la sequía no ha sido el único problema en torno a los usos del agua que han afrontado las sociedades a través de los siglos, por lo que sería una exageración - o una simplificación - afirmar que todas las obras hidráulicas que se han hecho en el transcurso de la historia han formado parte de una estrategia contra la sequía. Sin lugar a dudas, esa apreciación sería incorrecta. Lo que sí es cierto es que este tipo de obras coadyuvaron a disminuir los efectos del fenómeno en diferentes momentos de la historia, y con frecuencia se realizaron obras con el propósito de reducir las tensiones sociales y políticas provocadas por los malos tiempos (como sucedió, por ejemplo, con las obras de conservación del distrito de riego de Don Martín, Nuevo León, en los años cincuenta del siglo XX). Estas medidas permitían ocupar a los desempleados y otorgarles un salario, al mismo tiempo que hacían menos sensibles los efectos sociales de la crisis y contrarrestaban la depresión económica producida por ella. También es factible afirmar que los desarrollos tecnológicos en materia hidráulica, en general, se aceleran en tiempos de sequía y escasez de agua, debido a la necesidad de aprovechar mejor los pocos recursos hídricos disponibles; así, la sequía puede ser considerada como "el gran motor" del desarrollo tecnológico relacionado con el sector hídrico (Velasco et al., 2005). El avance de la tecnología a través de los siglos ha propiciado que las obras hidráulicas y los dispositivos utilizados para el aprovechamiento del agua sean cada vez más eficientes y sofisticados. El ejemplo más conspicuo es, probablemente, el uso del riego para la producción agrícola, que ha evolucionado de forma notable en el correr de los siglos hasta llegar a los modernos sistemas de riego presurizados y automatizados (aunque en la mayor parte de la superficie agrícola de México se 
siguen utilizando los métodos tradicionales de riego por gravedad). Por ello, Maass y Anderson (1978, p. 3) aseveran que "el riego es la respuesta humana a la sequía, por este medio se reduce radicalmente la incertidumbre que la naturaleza presenta al asentamiento humano en un medio ambiente poco acogedor."

Por otra parte, un aspecto sobresaliente que se observa en las distintas etapas del desarrollo del país (sobre todo a partir de la época colonial y hasta el siglo XX) es que a través de la historia las autoridades gubernamentales han impuesto diversos ordenamientos y regulaciones (controles de precios y existencias de los granos, prohibiciones para la extracción de semillas, etcétera) para tratar de aminorar los impactos de la sequía en la economía y la sociedad. En este aspecto, es importante hacer notar que existen continuidades entre los distintos periodos analizados, en particular entre el periodo colonial y el siglo XIX, y entre este y el siglo XX. Los estudiosos de los usos del agua coinciden en la larga y compleja continuidad de los ordenamientos coloniales con las nuevas normas republicanas, y algo similar sucede en torno a la gestión de las sequías. Por ejemplo, la prohibición de llevar semillas de las villas hacia otros lugares y el establecimiento de controles para regular los precios y las existencias de granos eran ordenamientos que se practicaban en el periodo virreinal y continuaron en el siglo XIX. No obstante, estas medidas en realidad fueron poco efectivas (a la luz de la teoría económica actual de libre mercado, se consideran totalmente ineficaces), pues intentaban obligar a los acaparadores y especuladores de granos a aceptar la tasación de precios que imponían las autoridades. Pero como no se respetaban del todo estas disposiciones, se instauraron otras medidas con mejores resultados para paliar las crisis, al menos temporalmente: en el virreinato se optó por echar mano de los tributos reales para adquirir productos en especie y venderlos a precios moderados, y en el siglo XIX comenzó la importación de víveres del extranjero.

De igual modo, en diferentes etapas del desarrollo nacional se han creado instituciones y programas gubernamentales que, directa o indirectamente, han tenido como finalidad prevenir o mitigar los impactos de la sequía en la sociedad. Desde la fundación del pósito y la alhóndiga para evitar el acaparamiento y la monopolización de la venta de granos en el virreinato, pasando por la creación de los Almacenes Generales de Depósito para aminorar los efectos de la insuficiencia de cosechas en el siglo XIX, hasta la instauración de planes y programas nacionales contra la sequía en los siglos XX y XXI. Con respecto de estos últimos programas, cabe mencionar el Plan de Lucha Contra la Sequía, instituido en los años setenta del siglo XX, y el Programa Nacional Contra la Sequía, puesto en marcha en 2013, para hacer notar 
la diferencia sustancial entre ambos: el primero consistía básicamente en atender de manera reactiva los efectos de la sequía mediante el ofrecimiento de empleo temporal a los afectados por el desastre; el segundo pretende adoptar un enfoque preventivo orientado a la gestión del riesgo de sequía por medio de la planificación de medidas preventivas y de mitigación que podrán ser implementadas antes, durante o después del evento, en función de la gravedad del fenómeno (CONAGUA, 2014). Lo cierto es que, con independencia de su origen, enfoque o alcance, todos los programas gubernamentales creados con la finalidad de paliar los impactos de la sequía han sido útiles, en mayor o menor medida, en distintos momentos históricos del país, puesto que han contribuido a reducir las pérdidas y los daños colaterales provocados por la escasez y falta de agua (Florescano, 2000; Ortega-Gaucin, 2012). Por tal motivo, se debe seguir trabajando en mejorar y hacer más eficientes estos programas, así como establecerlos de manera permanente a través de la instauración de políticas públicas con una visión de largo plazo que trascienda los cambios de gobierno.

\section{Conclusiones}

La sequía es un peligro natural que puede ocasionar graves impactos en los distintos sectores socioeconómicos de un estado o una nación. Es capaz de perturbar drásticamente las actividades humanas, el desarrollo social y el ambiente, de lo cual ningún país, por desarrollado que sea, puede librarse por completo. México ha sufrido los efectos adversos de las sequías de manera frecuente y persistente. A través de su historia ha sido implementada una gran diversidad de medidas con el propósito de prevenir o atenuar sus impactos. Estas medidas van desde aquellas que tienden a influir directamente sobre el clima mediante actos mágicos y rogativas a dioses y santos, hasta el uso de tecnologías avanzadas y la instauración de políticas públicas nacionales para aminorar las repercusiones de la sequía en la economía y la sociedad. Aunque en la actualidad contamos con mayor conocimiento científico y desarrollo tecnológico para hacer frente a la sequía, lo cierto es que estas herramientas no constituyen por sí mismas la solución al problema, sino que, más bien, son complementarias de otras acciones y estrategias de corte político, económico y social que de manera conjunta contribuyen a aminorar los efectos perjudiciales del fenómeno. Pese a la lucha histórica de México frente a la sequía, esta no ha dejado, ni dejará, de ser un problema capital, por lo que es sustancial que tanto las autoridades gubernamentales como la población en general seamos 
conscientes de nuestra fragilidad ante el peligro y de la importancia de adoptar medidas preventivas y de adaptación que conduzcan a una gestión apropiada del riesgo, sobre todo en las zonas áridas y semiáridas del país, donde por naturaleza el agua es escasa y, por ello, son las más expuestas y vulnerables ante los embates de esta anomalía climatológica.

\section{BiBLIOGRAFÍA}

Aboites Aguilar, L., y Camacho Pichardo, G. (1996). Aproximación al estudio de una sequía en México. El Caso de Chapala-Guadalajara (1949-1958). En V. García Acosta (coord.). Historia y desastres en América Latina. Vol. 1. (pp. 259-275). Distrito Federal, México. Centro de Investigaciones y Estudios Superiores en Antropología Social. Recuperado de http://www.pronacose.gob.mx/Repositorio/ Documentos/Aboites_Aproximación\%20al\%20estudio\%20de\%20una\%20 sequ\%C3\%ADa\%20en\%20México.pdf.

Alcalá Gómez, M. L., y Ceja Ramírez, S. G. (2014). Que la visita de la virgen traiga la gracia a Chapala. Semanario Arquidiocesano de Guadalajara. Órgano de Formación e Información Católica, año XVII (julio): 4-7. Recuperado de http:// www.semanario.com.mx/ps/2014/07/la-laguna-de-chapala-rico-legado-enriesgo/.

Álvarez, X. (20 de mayo de 2012). Oficiarán misas para que llueva en Guanajuato. El Universal. Recuperado de http://archivo.eluniversal.com.mx/notas/848426.html. Arreguín Cortés, F.; López Pérez, M.; Ortega-Gaucin, D., e Ibáñez Hernández, O. (2016). La política pública contra la sequía en México: Avances, necesidades y perspectivas. Tecnología y Ciencias del Agua, 7(5): 63-76. Recuperado de http:// repositorio.imta.mx/handle/20.500.12013/1705.

Ayala Carcedo, F. J. (2002). Catástrofes naturales, mitos, religiones e historia. en F. J. Ayala Carcedo y J. Olcina Cantos (coords.). Riesgos naturales (pp. 103-124). Barcelona, España: Ariel.

Bassie Sweet, K. (1991). From the Mouth of The Dark Cave: Commemorative Sculpture of The Late Classic Maya. Norman, Oklahoma, Estados Unidos: University of Oklahoma Press.

Below, R.; Grover Kopec, E., y Dilley, M. (2007). Documenting Drought-Related Disasters. A Global Reassessment. The Journal of Environment \& Development, 16(3): 328-344. DOI: https://doi.org/10.1177/1070496507306222. 
Bistráin, P. (1997). La evolución de las obras hidráulicas en los ríos Conchos y San Pedro. En L. Aboites Aguilar (ed.). Pablo Bistráin, ingeniero mexicano (pp. 42-48). Jiutepec, Morelos, México: Instituto Mexicano de Tecnologías del Agua, Centro de Investigaciones y Estudios Superiores en Antropología Social.

Castorena, G. (1980). Las sequías en el siglo XX. En G. Padilla, L. Rodríguez, G. Castorena y E. Flores Cano (coords.). Análisis histórico de las sequias en México (pp. 59-81). Distrito Federal, México: Secretaría de Agricultura y Recursos Hidráulicos, Comisión del Plan Nacional Hidráulico.

Ceja Ramírez, S. G. (2011). Chapala se alista para recibir a La Generala. Semanario Arquidiocesano de Guadalajara. Órgano de Formación e Información Católica, año XIV (junio): 4-6. Recuperado de http://www.semanario.com.mx/ps/2011/06/ chapala-se-alista-para-recibir-a-la-generala/.

Cook, E. R.; Seager, R.; Cane, M. A., y Stahle, D. W. (2007). North American Drought: Reconstructions, Causes, and Consequences. Earth-Science Reviews, 81(1): 93-134. Recuperado de http://ocp.ldeo.columbia.edu/res/div/ocp/pub/cook/ Cook_Seager_Cane_Stahle.pdf.

CONAGUA (Comisión Nacional del Agua) (2010). Reglas de organización y funcionamiento de los consejos de cuenca. Distrito Federal, México: Secretaría de Medio Ambiente y Recursos Naturales, Comisión Nacional del Agua.

CONAGUA (Comisión Nacional del Agua) (2014). Política pública nacional para sequias.

Documento rector. Distrito Federal, México: Secretaría de Medio Ambiente y Recursos Naturales, Comisión Nacional del Agua.

Culbert, T. P. (1973) The Classic Maya Collapse. Albuquerque, Nuevo México, Estados Unidos: University of New Mexico Press.

Dalmin, B. H. (1983). Climate and Prehistory on the Yucatan Peninsula. Climatic Change 5(3): 245-264. DOI: https://doi.org/10.10007/BF02423521.

Del Bajío, A. (1987). Crisis alimentarias y subsistencias populares en México. Distrito Federal, México: Compañía Nacional de Subsistencias Populares.

Doolittle, W. E. (1999). Noria Technology in Mexico: Against the Current and Against the Odds. International Molinology, 59: 8-13.

El Redactor de Soto La Marina (5 de mayo de 2013). Convocan a procesión por la fiesta de San Isidro Labrador. Recuperado de http://www.elredactor.mx/index.php/ locales/85-ultimas/18155-convocan-a-procesion-por-la-fiesta-de-san-isidro-labrador.

Enge, K. I., y Whiteford, S. (1989). The Keepers of Water and Earth: Mexican Rural Social Organization and Irrigation. Austin, Texas, Estados Unidos: University of Texas Press. 
Escobar Ohmstede, A. (1997) Las "sequías" y sus impactos en las sociedades del México decimonónico, 1856-1900. En V. García Acosta (coord.). Historia y desastres en América Latina. Vol. 2. (pp. 170-202). Distrito Federal, México: Centro de Investigaciones y Estudios Superiores en Antropología Social.

Escobar Ohmstede, A. (2004). Desastres agricolas en México. Catálogo histórico. Tomo II. Siglo XIX (1822-1900). Distrito Federal, México: Fondo de Cultura Económica, Centro de Investigaciones y Estudios Superiores en Antropología Social.

IFRC (International Federation of Red Cross and Red Crescent Societies) (2014). Informe mundialsobre desastres: Cultura y riesgo. Ginebra, Suiza: International Federation of Red Cross and Red Crescent Societies.

Florescano, E. (1986). Precios del maizy crisis agricolas en México, 1708-1810. Distrito Federal, México: Ediciones Era.

Florescano, E. (2000). Breve historia de la sequia en México. Distrito Federal, México: Consejo Nacional para la Cultura y las Artes.

Florescano, E.; Sancho y Cervera, J., y Pérez Gavilán Arias, D. (1980). Las sequías en México: Historia, características y efectos. Comercio Exterior, 30(7): 747-757. Recuperado de http://revistas.bancomext.gob.mx/rce/magazines/421/9/RCE9.pdf. GAARDER, J. (2012). Elmundo de Sofia: Novela sobre la historia de la filosofia. Trad. Kirsti Baggethum y Asunción Lorenzo. Madrid, España: Ediciones Siruela.

García Acosta, V. (1993). Las sequías históricas de México. Desastres y Sociedad, I(julio-diciembre): 2-18. Recuperado de http://www.desenredando.org/public/ revistas/dys/rdys01/dys1-LSHM-oct-24-2001.pdf.

García Acosta, V.; Pérez Cevallos, J. M., y Molinar del Villar, A. (2003). Desastres agricolas en México. Catálogo histórico. Tomo I. Época prehispánica y colonial (958-1822). Distrito Federal, México: Fondo de Cultura Económica, Centro de Investigaciones y Estudios Superiores en Antropología Social.

García Hernández, A. (1997). Alternativas ante las sequías de 1789-1810 en la Villa de Saltillo, Coahuila, México. En V. García Acosta (coord.). Historia y desastres en América Latina. Vol. 2 (pp. 148-169). Distrito Federal, México: Centro de Investigaciones y Estudios Superiores en Antropología Social.

García Jiménez, F.; Fuentes Mariles, O., y Matías Ramírez, L. G. (2002). Sequias. Distrito Federal, México: Centro Nacional de Prevención de Desastres.

Galván Rivera, M. (1998). Ordenanzas de tierras y aguas. Facsímil de la 5 a edición de 1868. Presentación de Teresa Rojas Rabiela. Distrito Federal, México: Centro de Investigaciones y Estudios Superiores en Antropología Social, Archivo Histórico del Agua, Registro Agrario Nacional. 
Garza Merodio, G. G. (2002). Frecuencia y duración de sequías en la cuenca de México de fines del siglo XVI a mediados del XIX. Investigaciones Geográficas, 48 (agosto): 106-115. Recuperado de http://www.scielo.org.mx/scielo.php?script=sci_arttext \&pid=S0188-46112002000200007.

GiLl, R. B. (2008). Las grandes sequias mayas. Agua, vida y muerte. Distrito Federal, México: Fondo de Cultura Económica.

Gresham Chapman, J. (1975). La construcción del ferrocarril mexicano (1837-1880). Distrito Federal, México: Secretaría de Educación Pública.

Hernández Rodríguez, R. (1982). Epidemias y calamidades en el México prehispánico. En E. Florescano y E. Malvido (comps.). Ensayo sobre la historia de las epidemias en México. Tomo 1 (pp. 144-152). Distrito Federal, México: Instituto Mexicano del Seguro Social.

Hodell, D. A.; Jason H. Curtis y Brenner, M. (1995). Possible Role of Climate in the Collapse of Classic Maya Civilization. Nature. International Journal of Science, 375(June): 391-394. DOI: 10.1038/375391a0.

IPCC (Intergovernmental Panel on Climate Change) (2014). Climate Change 2014: Impacts, Adaptation and Vulnerability. Ginebra, Suiza: World Meteorological Organization, United Nations Environment Progrmme.

INEGI (Instituto Nacional de Estadística y Geografía) (2013). Estadísticas a propósito del día mundial contra la desertificación y la sequía. México, Distrito Federal: Instituto Nacional de Estadística y Geografía Recuperado de http://www.inegi.org.mx/ inegi/contenidos/espanol/prensa/Contenidos/estadisticas/2013/sequia0.pdf.

Kıм, T. W.; Valdés, J. B., y Aparicio, J. (2002). Frequency and Spatial Characteristics of Droughts in the Conchos River Basin, Mexico. Water International, 27(3): 420430. DOI: https://doi.org/10.1080/02508060208687021.

Kroger, J., y Granziera, P. (2012). Aztec Goddesses and Christian Madonnas. Images of the Divine Feminine in Mexico. Farnham, Inglaterra: Ashgate.

LEAN, J., y Rind, D. (2001). Earth's Response to a Variable Sun. Science, 292(5515): 234236. DOI: $10.1126 /$ science. 1060082 .

Liverman, D. M. (2000). Adaptation to Drought in Mexico. En D. Wilhite (ed.).Drought: A Global Assessment.Vol. II. (pp. 31-45). Nueva York, Estados Unidos: Routledge. Maass, A., y Anderson, R. L. (1978) ...And the Desert Shall Rejoice. Conflict, Growth and Justice in Arid Environments. Cambridge, Reino Unido: The MIT Press.

Melchor, E. (14 de julio de 2013). Piden por recuperación del lago de Chapala. El Informador. Recuperado de http://www.informador.com.mx/jalisco/2013/471714/6/. 
Molina Del Villar, A. (1996). Impacto de epidemias y crisis agrícolas en comunidades y haciendas del México colonial (1737-1742). En V. García Acosta (coord.). Historia y desastres en América Latina. Vol. 1 (pp. 146-166). Distrito Federal, México: Centro de Investigaciones y Estudios Superiores en Antropología Social. Moreno, P. (2004). Nubes ausentes: Las sequias. Distrito Federal, México: Editorial Planeta Mexicana.

Mishra, A. K., y Vijay P. Singh (2010). A Review of Drought Concepts. Journal of Hydrology, 391(1-2): 202-216. DOI: https://doi.org/10.1016/jhydrol.2010.07.012. Musset, A. (1991). De l'eau vive à l'eau morte: Enjeux techniques et culturels dans la Vallée de Mexico (XVIe-XIXe siècles). París, Francia: Éditions Recherche sur les Civilisations.

Ortega-Gaucin, D. (2012). Sequía en Nuevo León: Vulnerabilidad, impactos y estrategias de mitigación. Apodaca, Nuevo León, México: Instituto del Agua del Estado de Nuevo León.

Ortega-Gaucin, D., y Velasco, I. (2013). Aspectos socioeconómicos y ambientales de las sequías en México. Aqua- $L A C, 5(2): 78-90$. Recuperado de https://agua.org. $\mathrm{mx} /$ wp-content/uploads/2014/06/Aspectos_socioeconomicos_y_ambientales_de_las_sequias_en_Mexico.pdf.

Padilla, G.; Rodríguez, L.; Castorena, G., y Florescano, E. (1980). Análisis histórico de las sequias en México. Distrito Federal, México: Secretaría de Agricultura y Recursos Hidráulicos, Comisión del Plan Nacional Hidráulico.

Palerm, A. (1954). La distribución del regadío en el área central de Mesoamérica. Ciencias Sociales, 5(25): 2-15.

Palerm, A. (1969). The Agricultural Basis of Urban Civilization in Mesoamerica. En J. A. Graham (ed.). Ancient Mesoamerica: Selected Readings (pp. 60-74). Palo Alto, Santa Clara, California, Estados Unidos: Peek Publications.

Palerm, A. (2007). Agua y agricultura: Angel Palerm, la discusión con Karl Wittfogel sobre el modo asiático de producción y la construcción de un modelo para el estudio de Mesoamérica. Distrito Federal, México: Universidad Iberoamericana, Agencia Española de Cooperación Internacional, Dirección General de Relaciones Culturales y Científicas.

Palerm, A., y Wolf, E. R. (1972). Agricultura y civilización en Mesoamérica. Distrito Federal, México: Secretaría de Educación Pública.

Pellicer de Brody, O., y Mancilla, E. L. (1980). El entendimiento con los Estados Unidos y la gestación del desarrollo estabilizador (1952-1960). Historia de la Revolución Mexicana, 23: 122-124. 
Presidencia de la República (2012a). Acuerdo por el que se instruyen acciones para mitigar los efectos de la sequía que atraviesan diversas entidades federativas. Diario Oficial de la Federación 25/01/2012. Recuperado de http://www.dof.gob.mx/ nota_detalle.php?codigo $=5231010 \&$ fecha $=25 / 01 / 2012$.

Presidencia de la República (2012b). Lineamientos que establecen los criterios y mecanismos para emitir acuerdos de carácter general en situaciones de emergencia por la ocurrencia de sequía. Diario Oficial de la Federación 31/10/2012. Recuperado de http://www.dof.gob.mx/nota_detalle_popup.php?codigo=5278695.

Quezada RAmírez, M.N. (1996).Los matlatzincas. Época prehispánica yépoca colonial hasta 1650. Distrito Federal, México: Universidad Nacional Autónoma de México.

Reyes Osorio, S. (1974). Consumos aparentes de productos agrícolas 1925-1978. Ecotecnia, 3(9): 152-170.

Rodríguez O., J. E., y MacLachlan, C. M. (2001). Hacia el ser histórico de México. Una reinterpretación de la Nueva España. Distrito Federal, México: Diana.

Rojas Rabiela, T. (2009). Las obras hidráulicas en las épocas prehispánica y colonial. En Comisión Nacional del Agua (comp.). Semblanza histórica del agua en México (pp. 9-25). Distrito Federal, México: Secretaría de Medio Ambiente y Recursos Naturales. Recuperado de http://www.conagua.gob.mx/CONAGUA07/ Publicaciones/Publicaciones/SGP-28SemblanzaHistóricaMéxico.pdf.

Rossi, G.; Castiglione, L., y Bonaccorso, B. (2007). Guidelines for Planning and Implementing Drought Mitigation Measures. En G. Rossi, T. Vega y B. Bonaccorso (eds.). Methods and Tools for Drought Analysis and Management (pp. 325-347). Dordrecht, Países Bajos: Springer.

SÁnchez Rodríguez, M. (2009). De la tradición a la modernidad. Cambios técnicos y tecnológicos en los usos del agua. En Comisión Nacional del Agua (comp.). Semblanza histórica del agua en México (pp. 27-41). Distrito Federal, México: Secretaría de Medio Ambiente y Recursos Naturales. Recuperado de https://agua. org.mx/wp-content/uploads/2010/09/semblanzahistoricaaguaenmexico.pdf.

Schubert, S. D.; Suárez M. J.; Pegion, P. J.; Koster, R. D., y Bacmeister, J. T. (2004). Causes of Long-Term Drought in the U.S. Great Plains. Journal of Climate, 17(3): 485-503. DOI: https://doi.org/10.1175/1520-0442(2004)017<0485:CO LDIT>2.0.CO;2.

SEGOB (Secretaría de Gobernación) (2012). FONDEN: El Fondo de Desastres Naturales de México. Una reseña. Distrito Federal, México: Banco Mundial, The Global Facility for Disaster Reduction and Recovery, Swiss Confederation, Secretaría de Gobernación, Secretaría de Hacienda y Crédito Público. Recuperado de 
http://www.proteccioncivil.gob.mx/work/models/ProteccionCivil/Almacen/ fonden_resumen_ejecutivo.pdf.

Sheffield, J.; Andreadis, K. M.; Wood, E. F., y Lettenmaier, D. P. (2009). Global and Continental Drought in the Second Half of the Twentieth Century: SeverityArea-Duration Analysis and Temporal Variability of Large-Scale Events.Journal of Climate, 22(8): 1962-1981. DOI: https://doi.org/10.1175/2008JCLI2722.1.

SRH (Secretaría de Recursos Hidráulicos) (1952). Informe de Labores de la Secretaría de Recursos Hidráulicos. Del $1^{\circ}$ de septiembre de 1951 al 31 de agosto de 1952. Distrito Federal, México: Talleres Gráficos de la Nación.

Senior, C. (1956). Reforma agraria y democracia en la Comarca Lagunera. Problemas Agricolas e Industriales de México, 8(2): 3-174.

Toussainnt, M. (1974). Arte colonial en México. Distrito Federal, México: Universidad Nacional Autónoma de México.

VÁzQUez de Warman, I. (1968). El pósito y la alhóndiga en la Nueva España. Historia Mexicana, 17(3): 395-426. Recuperado de http://historiamexicana.colmex.mx/ index.php/RHM/article/view/1161/1052.

Velasco, I.; Ochoa, L., y Gutiérrez, C. (2005). Sequía, un problema de perspectiva y gestión. Región y Sociedad, 17(34): 35-71. DOI: https://doi.org/10.22198/ rys.2005.34.a615.

Wilhite, D. A. (2000). Drought as a Natural Hazard: Concepts and Definitions. En D. A. Wilhite (ed.). Drought: A Global Assessment.Vol. I (pp. 3-18). Nueva York, Estados Unidos: Routledge.

Wilhite, D. A., y Vanyarkho, O. (2000). Drought: Pervasive Impacts of a Creeping Phenomenon. En D. A. Wilhite (ed.). Drought: A global Assessment. Vol. I (pp. 245-255). Nueva York, Estados Unidos: Routledge.

Wilken, G. C. (1987). The Good Farmers: Traditional Agricultural Resource Management in Mexico and Central America. Berkeley, California, Estados Unidos: University of California Press.

Wolf, E. R. (1967). Pueblos y culturas de Mesoamérica. Distrito Federal, México: Ediciones Era.

WMO (World Meteorological Organization) (2006). Vigilancia y alerta temprana de la sequia: Conceptos, progresos y desafios futuros. Ginebra, Suiza: World Meteorological Organization. Recuperado de http://www.droughtmanagement.info/literature/ WMO_drought_monitoring_early_warning_es_2006.pdf.

WMO (World Meteorological Organization) (2012). International Glossary of Hidrology. Ginebra, Suiza: World Meteorological Organization, United Nations Educational, 
Scientific and Cultural Organization. Recuperado de http://www.wmo.int/pages/ prog/hwrp/publications/international_glossary/385_IGH_2012.pdf.

Zapata Peraza, R. L. (1982). Los chultunes. Sistemas de captación y almacenamiento de agua pluvial. Distrito Federal, México: Instituto Nacional de Antropología e Historia. 